\title{
The Use of Medications for Cognitive Enhancement
}

\author{
William Pryse-Phillips, Shelley Sternberg, Paula Rochon, Gary Naglie, \\ Howard Strong, John Feightner
}

\begin{abstract}
Objective: To provide Canadian physicians and allied health care professionals with the evidence they need to help them make treatment decisions in the management of patients with Alzheimer's disease or other dementias. Options: The full range and quality of diagnostic and therapeutic modalities available to Canadian physicians for the management of dementia. Outcomes: Improvement in the treatment of dementias, leading to reduced suffering, increased functional capacity and decreased economic burden. Evidence and values: The creation of these evidence-based consensus statements involved literature reviews of the subject by the authors; comparison of alternative clinical pathways and description of the methods whereby published data were analyzed; definition of the level of evidence for data in each case; evaluation and revision in a conference setting (involving primary care physicians, neurologists, psychiatrists, geriatricians, psychologists, consumers and other interested parties); insertion of tables showing key variables and data from various studies and tables of data with recommendations; and reassessment by all authors. Benefits, harms, and costs: A rational plan for the therapy of dementias is likely to lead to substantial benefits in both human and economic terms. Recommendations: Treatment decisions should be made taking into account the severity or stage of the disease, the availability of caregivers, the presence of disease affecting other bodily systems and the ability of the subject to pay the cost of the medications. Donepezil is considered to have positive effects upon certain tests of neuropsychological function and may produce some improvement in Alzheimer's disease of mild to moderate severity as measured by rating scales. Its ability to improve quality of life remains uncertain. No other drug treatments* (apart from symptomatic therapies) are at present approved for the treatment of Alzheimer's disease. Validation: These recommendations were created by a writing committee, evaluated and revised at a consensus conference and further reviewed and revised by the writing committee prior to publication.
\end{abstract}

RÉSUMÉ: L'utilisation de médicaments pour améliorer la fonction cognitive. Objectif: Fournir aux médecins canadiens et aux autres professionnels de la santé les informations dont ils ont besoin pour les aider à prendre des décisions de traitement dans la prise en charge de patients atteints de la maladie d'Alzheimer ou d'autres démences. Options: La gamme complète et la qualité des modalités diagnostiques et thérapeutiques dont disposent les médecins Canadiens pour la prise en charge de la démence. Résultats: L'amélioration du traitement des démences, diminuant ainsi la souffrance, augmentant la capacité fonctionnelle des patients et diminuant le fardeau économique. Évidence et valeurs: La création de ces énoncés consensuels basés sur les données actuelles de la science a nécessité des revues de littérature sur le sujet par les auteurs; une comparaison des thérapies alternatives et une description des méthodes d'analyse des données publiées; une définition du niveau de preuve dans chaque cas; une évaluation et une révision en conférence (impliquant des médecins de première ligne, des neurologues, des psychiatres, gériatres, psychologues, consommateurs et autres parties intéressées); l'inclusion de tables montrant les variables clé et les données de différentes études et des tables de données avec recommandations; et une réévaluation par tous les auteurs. Bénéfices, désavantages et coûts: Un plan rationnel pour le traitement des démences est susceptible de mener à des bénéfices substantiels au point de vue humain et économique. Recommandations: Les décisions de traitement devraient être prises en tenant compte de la sévérité ou du stade de la maladie, de la disponibilité des aidants, de la présence de maladies d'autres systèmes et de la capacité du sujet à payer le coût de la médication. Le donépézil aurait des effets positifs sur certains tests de fonction neuropsychologique et peut produire une amélioration dans la maladie d'Alzheimer de sévérité légère à modérée. Sa capacité d'améliorer la qualité de vie demeure incertaine. Aucune autre médication (sauf les traitements symptomatiques) n'est actuellement approuvée pour le traitement de la maladie d'Alzheimer. Validation: Ces recommandations ont été élaborées par un comité de rédaction, évaluées et révisées à une conférence de consensus, revues et révisées de nouveau par le comité de rédaction avant la publication.

Can. J. Neurol. Sci. 2001; 28: Suppl. 1 - S108-S114

Following the introduction of the first medication approved in Canada for the therapy of Alzheimer's disease (AD), the Canadian Consensus Conference on Dementia (held in February 1998) felt it appropriate to survey agents for which therapeutic claims have been made in this field. At that conference, the authors produced a detailed document surveying anti-dementia
From Memorial University, St. John's, Newfoundland, Canada (WP-P), Department of Medicine, Section of Geriatrics, University of Chicago, USA(SS), Department of Medicine, University of Toronto, Ontario (PR, GN), Department of Psychiatry, Memorial University, St. John's, Newfoundland (HS), University of Western Ontario, London ON (JF), Canada.

Reprint requests to: Paula A. Rochon, Kunin-Lunenfeld Applied Research Unit, Baycrest Centre for Geriatric Care, 3560 Bathurst Street, Toronto, Ontario M6A2E1 Canada

* See Brief Review: Rivastigmine, A Second Cholinesterase Inhibitor - pg S122 
drugs. The following is a synopsis of our survey of drugs currently considered.

\section{METHODS}

We performed a MEDLINE search of the literature from 1986 to March 1998 in order to identify all randomized controlled trials (RCTs) of tacrine, selegiline, vitamin E, donepezil or ginkgo and dementia. We also sought data on hydergine and propentofylline. The search was updated in October of 2000. Only those trials with cognitive outcome measures were assessed. All studies evaluating combinations of therapies were excluded unless the results were presented separately for each therapy. Excluding articles that did not meet inclusion criteria, 24 remained for review. By contacting behavioural neurology experts we identified 15 further articles. All reference lists from the articles retrieved in the MEDLINE search were scanned and reviewed. Of the 44 original papers, 27 remained. We were unable to obtain three papers but included the information from the abstract of one of them, leaving 25 articles. Following the updated search an additional five RCTs were identified. In total, 30 trials were included in our sample.

Following the creation of an initial draft review, all authors had the opportunity to contribute further sections and then to review the whole draft paper, amending it as they saw fit. A final draft was circulated to the co-authors and agreed upon prior to the conference, in which all participated. The results of the review were presented to the conference and agreed as amended after debate. The principles and guidelines set out in this document were then adopted.

The criteria for assigning levels of evidence and grades of

Table 1: Criteria for assigning levels of evidence and grades of recommendation

\section{Level Criteria}

1 Evidence obtained from at least one properly randomized controlled trial.

2 Evidence obtained from well-designed controlled trials without randomization

Evidence obtained from well-designed cohort or case-control analytic studies, preferably from more than one centre or research group.

Evidence obtained from comparisons between times or places with or without the intervention. Dramatic results in uncontrolled experiments are included in this category.

3 Opinions of respected authorities, based on clinical experience, descriptive studies or reports of expert committees.

\section{Grade Criteria}

A There is good evidence to support this manoeuvre.

B There is fair evidence to support this manoeuvre.

C There is insufficient evidence to recommend for or against this manoeuvre, but recommendations may be made on other grounds.

D There is fair evidence to recommend against this procedure.

E There is good evidence to recommend against this procedure. recommendations used in this manuscript were developed at the Canadian Consensus Conference on Dementia and are listed in Table 1. The committee used the Canadian Medical Association's clinical practice guidelines ${ }^{1}$ and the rules of evidence used by the committee were consistent with the Canadian Task Force on the Periodic Health Examination as previously used. ${ }^{2}$ The full methods used in the consensus development process are published elsewhere. ${ }^{3}$

\section{THERAPIES FOR COGNITIVE ENHANCEMENT}

\section{Tacrine}

In two early studies ${ }^{4,5}$ tacrine did not lead to useful improvement in cognition, functional status or behaviour. Over 1100 patients, with mild to moderate probable AD, were randomized by Gracon ${ }^{6}$ to receive placebo or tacrine for 12 or 30 weeks. Outcome measures included objective assessments of cognitive function, qualitative assessments of treatment response from the caregiver and clinician perspective, and assessments of activities of daily living (ADL). Statistically significant treatment effects favoring tacrine were demonstrated in each domain but these tended to be subtle, ranging from improvement to stabilization or slowed decline.

Knapp et $\mathrm{al}^{7}$ evaluated the efficacy and safety of three doses of tacrine in patients with mild to moderate AD in a 30 -week trial, using as primary outcome measures the Clinician Interview-Based Impression (CIBI), Alzheimer Disease Assessment Scale - Cognitive (ADAS-Cog) and a Final Comprehensive Consensus Assessment (FCCA). Only 263 of 653 patients included in an intent-to-treat (ITT) analysis had evaluable data at 30 weeks. The ITTanalysis revealed significant $(\mathrm{P} \leq .05)$ dose-response trends and between-group comparisons on the CIBI and ADAS-Cog but these were modest - on the CIBI, $23 \%$ improved on tacrine and $17 \%$ on placebo. In the evaluable patients, dose-response trends in favor of $160 \mathrm{mg} / \mathrm{d}$ of tacrine were observed for all three primary measures $(\mathrm{P} \leq .001)$. The authors concluded that tacrine produced dose-related improvements on objective tests, global evaluations and measures of quality of life and that the large number of patient withdrawals did not bias the overall conclusions.

Raskind et $\mathrm{al}^{8}$ examined the effects of tacrine in patients with mild to moderate AD who had been enrolled in a previous trial and had taken placebo or $160 \mathrm{mg} / \mathrm{d}$ of tacrine. The main outcome measure was a change from baseline to last observation carried forward in discrete subscale scores of the ADAS, both cognitive and noncognitive. Improvement was defined as a decrease of at least one point from baseline. Compared with the placebo group the percentage of patients receiving tacrine whose conditions improved by one ADAS point or more, or stabilized, was significantly greater for eight psychological measures and on scores for cooperation, delusions and pacing.

Knopman et $\mathrm{al}^{9}$ assessed the possible association between tacrine dose and likelihood of nursing home placement or death in patients with $\mathrm{AD}$ in an unblinded study following a 30 -week RCT. Patients who remained on tacrine at doses $>80 \mathrm{mg} / \mathrm{d}$ for a minimum of two years were less likely to have entered a nursing home than were patients on lower doses.

Watkins et $\mathrm{al}^{10}$ showed that among 2,446 patients with mild or moderate $\mathrm{AD}$ exposed to tacrine in clinical trials conducted in 
the United States, Canada and France, serum alanine aminotransferase (ALT) levels greater than the upper limit of normal occurred on at least one occasion in 1,203 patients (49\%), levels greater than three times the upper limit of normal occurred in $25 \%$, and levels greater than 20 times the upper limit occurred in $2 \%$ of patients. Ninety percent of all ALT levels greater than three times the upper limit of normal occurred during the first 12 weeks of treatment. In all instances, discontinuation of tacrine therapy reversed any elevations in ALT levels.

Recommendation: The value of tacrine for symptomatic therapy in patients with AD is uncertain and its side-effect profile is cause for concern. While approved in the United States and in some European countries, we concur with the assessment made by the Health Protection Branch which rejected the drug on the grounds that the demonstrated benefits in certain test parameters did not translate into sufficient functional improvement to offset its potential risks. Level 1, Class D.

\section{Donepezil}

This agent has been evaluated in six RCTs, one with an open label extension. In a multicentre double-blind placebo-controlled RCT, Rogers et $\mathrm{al}^{11}$ examined the safety and efficacy of 1,3 or 5 $\mathrm{mg}$ of donepezil compared to placebo for 12 weeks in 161 outpatients with a diagnosis of probable AD. The subjects had a Mini-Mental State Examination (MMSE) score between 10 and 26, a mean age of about 71 years and no significant medical illness. Donepezil (5 mg. od.) significantly improved cognition, as measured by an adjusted mean decrement from baseline in the ADAS-Cog scale of 2.5 points, compared to placebo and an adjusted mean increase from baseline of two points on the MMSE scale (a secondary outcome measure ) when compared to the 1 mg dose of donepezil (but not when compared to placebo). The Clinician's Global Impression of Change (CGIC) was the primary outcome measure. Functional, quality of life, and disease severity parameters were not significantly affected. The incidence of adverse effects did not differ between the donepezil and placebo groups. Donepezil use was not associated with hepatotoxicity.

In an open-label extension of the above for up to 192 weeks, and using the same efficacy measures in 132 members of the original patient group, Rogers and Friedhof ${ }^{12}$ reported a reduction in the rate of cognitive and global decline of patients in mild-to-moderate stages compared to that expected in light of the natural history of the disease. Because the original RCT had demonstrated a large placebo effect, comparison with natural history controls may be inappropriate.

Rogers et $\mathrm{al}^{13}$ evaluated the efficacy and safety of donepezil in patients with mild to moderate AD in RCT conducted at 20 investigational sites in the United States. Patients were assigned to either placebo or donepezil at a 5 or a $10 \mathrm{mg}$ dose. The primary outcome measures included the cognitive portion of the ADAS, and the Clinician's Interview Based Impression of Change-Plus (CIBIC-Plus). Cognitive function (measured using the ADAS-Cog was significantly improved in the donepezil treated group relative to the placebo groups at 12, 18, and 24 weeks. Adverse effects appeared to be more common with increasing dose of donepezil.

In a similar study, Burns et $\mathrm{al}^{14}$ evaluated the efficacy of donepezil in 82 sites internationally, including Canada and the United Kingdom, using a 30 week RCT. A total of 818 patients were randomized in this study. Again improvement were seen in the ADAS-Cog scores in patients receiving donepezil relative to those in the placebo group.

Rogers et $\mathrm{al}^{15}$ evaluated donepezil in a randomized placebo controlled trial. This study was conducted at 23 centres in the United States and patients were randomized to placebo or donepezil at doses of either 5 or $10 \mathrm{mg}$ for a period of 12 weeks. This study evaluated 468 patients with mild to moderately severe AD. Relative to placebo, donepezil produced statistically significant improvements in the ADAS-Cog, CIBIC-Plus and the MMSEs. The mean donepezil to placebo differences for the group receiving $10 \mathrm{mg}$ of donepezil were 3.1 units for the ADAS-Cog ( $<<.001) ; 0.4$ units for CIBIC-Plus ( $\mathrm{p}<.008)$; and 1.3 units for the MMSE ( $p<.004)$.

Most recently, Greenberg et al ${ }^{16}$ evaluated donepezil therapy at memory disorders units at the Massachusetts General Hospital and the Brigham and Women's Hospital in Boston. In this study, 60 older adults with probable AD were randomized in a 24-week cross-over study to donepezil or placebo in one of two sequences. Donepezil was administered in a $5 \mathrm{mg}$ dose. Test results using the ADAS-Cog were significantly improved during treatment with donepezil and slightly worse in the placebo group. Nine patients withdrew from the study after randomization. Of these, two were judged to have serious adverse events possibly related to donepezil (syncope and seizure). Of patients completing the study, gastrointestinal adverse effects were the most common reported problems.

Recommendation: At present, donepezil is the only drug approved for the treatment of mild-moderate AD. Donepezil has been shown to lead to improvements in certain cognitive tests and in clinical global assessments. However, long term clinical benefits of maintaining functional independence and improving quality of life remain unclear. The studies excluded patients with important medical illnesses, so effectiveness may have been overestimated and side-effects underestimated in terms of the likely outcome in clinical practice. Level 1, Class B.

\section{Vitamin $\mathbf{E}$}

Only one double-blind RCT compared the use of vitamin E (alpha-tocopherol) to placebo in the treatment of moderate AD. Sano et $\mathrm{al}^{17}$ compared $2000 \mathrm{IU}$ of vitamin E vs. $10 \mathrm{mg} / \mathrm{d}$ of selegiline vs. both vs. placebo in 341 subjects over two years, to determine whether either or both of these antioxidants could delay disease progression. The primary outcome, defined as time to occurrence of any of death, institutionalization, loss of ability to perform activities of daily living or severe dementia, was negative (see following section). However, institutionalization was significantly delayed in the vitamin E group. Falls and syncope were notably more common in the treatment groups and there was no additive effect of combining therapies. Despite random assignment, the baseline score on the MMSE was higher in the placebo group than in the other three groups and this variable was highly predictive of the primary outcome. The study has been criticized $^{18}$ on the appropriateness of the end points, the statistical adjustments and internal consistency.

Recommendation: While vitamin $\mathrm{E}$ is reasonably safe, the benefits shown by the methodologically flawed trial appear modest, so there is insufficient evidence to recommend it for the treatment of AD. Level 1, Class C. 


\section{Selegiline}

Selegiline was compared to phosphatidylserine in 40 patients with mild to moderate AD in a three month RCT. ${ }^{19}$ The selegiline group showed significantly superior improvements compared to the others in most cognitive areas examined and appeared able to induce an increased degree of autonomy in day-to-day activities. Tolerability was good. Forty patients with mild-to-moderate AD were enrolled by Campi et $\mathrm{al}^{20}$ in a single-blind, RCT to assess the efficacy and safety of selegiline and L-acetylcarnitine in the treatment of AD over three months. Selegiline therapy led to a comparative global improvement in the processing, storage, and retrieval of given information, improvements in verbal fluency and visuospatial abilities.

Tariot et $\mathrm{al}^{21}$ examined the value to $10 \mathrm{mg}$ and $40 \mathrm{mg}$ of selegiline vs. placebo in 17 hospitalized patients with dementia and found decreases in anxiety and excitement and improvement in cognitive tasks with the $10 \mathrm{mg}$ dose. A study of 20 outpatients with $\mathrm{AD}$ comparing $10 \mathrm{mg}$ of selegiline to placebo, demonstrated improvements in memory and attention in patients followed for three months. Lawlor et $\mathrm{al}^{22}$ examined the behavioural and cognitive effects of selegiline in 25 behaviourally disturbed AD patients in a 14-week study of selegiline $(10 \mathrm{mg})$ and placebo. In the primary analysis, improvement on the Brief Psychiatric Rating Scale, the Dementia Mood Assessment Scale (DMAS) and the ADAS-Cog scores with selegiline treatment did not reach statistical significance. In a secondary analysis, it improved behaviour and cognition in a subset of testable patients.

Sano et al $^{17}$ studied 341 patients with moderate AD who received selegiline, alpha-tocopherol, both agents or placebo for two years. The primary outcome was the time to the occurrence of death, institutionalization, loss of the ability to perform basic ADL or attainment of a Clinical Dementia Rating score of 3. Despite random assignment, the baseline score on the MMSE was higher in the placebo group than in the other three groups, and this variable was highly predictive of the primary outcome. In the unadjusted analyses, there was no statistically significant difference in the outcomes among the four groups. However, in an adjusted analysis selegiline resulted in significant improvements compared to placebo. It was concluded that in patients with moderately severe impairment from AD disease, treatment with selegiline slows functional deterioration but that it has little effect on cognitive measures.

Following a six-month double-blind RCT, Finali et $\mathrm{al}^{23,24}$ concluded that selegiline improved cognitive functions and behaviour founded on memory efficiency and reported that selegiline significantly improves some memory parameters, probably through improvement in information processing abilities and in learning strategies at the moment of acquisition. Burke et $\mathrm{al}^{25}$ in a 15 -month double-blind RCT on 39 subjects with mild $\mathrm{AD}$, found that selegiline had a slight effect on a single measure of psychopathology but had no measurable impact on any other measure of behaviour or cognitive function and did not appear to slow the progression of the disease. Mangoni et $\mathrm{al}^{26}$ enrolled 119 patients with AD to assess the efficacy and tolerability of selegiline over three months and reported that it improved cognitive functions and reduced behavioural alterations. Freedman et al, ${ }^{27}$ in a carefully-designed RCT found that oral selegiline provided no detectable benefit on general behaviour, neuropsychiatric symptoms or cognitive functions in patients with $\mathrm{AD}$ treated for six months.

Filip et $\mathrm{al}^{28}$ conducted a randomized placebo control study in nursing homes located in seven cities in Czechoslovakia to evaluate the benefit of selegeline relative to placebo in improving cognitive function. A total of 173 nursing home residents were evaluated. After 24 weeks of treatment, the subset of patients with normal results on the clock drawing test who were treated with selegeline had improved MMSE scores relative to those treated with placebo.

Recommendation: Selegiline has only been found effective in the treatment of $\mathrm{AD}$ when secondary analyses were performed. There is insufficient evidence that this agent leads to clinically important improvements in AD. Level 1, Class $C$.

\section{Ginkgo biloba}

Two double-blind placebo-controlled RCTs compared the use of ginkgo biloba (a plant extract with antioxidant properties) to placebo in patients with mild to moderate $\mathrm{AD}$ or multi-infarct dementia. In a German study, Kanowski et aR $^{29}$ compared the use of $240 \mathrm{mg}$ per day of a standardized ginkgo preparation (EGb 761 ) to placebo in 222 healthy outpatients for 24 weeks. Only 156 subjects $(70 \%)$ completed the trial, but incomplete information is provided as to the reasons for dropout. Outcome measures were global assessment, attention/memory, and ADL scales. The primary outcome measure was the therapeutic responder rate, defined as a change in scale score of at least one standard deviation from the baseline mean on at least two of the three outcome measures. This is not a standard outcome measure in North America and its validity is uncertain. The rate in the ginkgo group was $28 \%$ (22 subjects) compared to $10 \%$ (eight subjects) in the placebo group $(\mathrm{p}<0.01)$. For individual outcome variables, statistically significant differences favoring ginkgo were found in the clinical global assessment and attention/memory scales, but not in the ADLscale.

In a North American study on this agent, Le Bars et $\mathrm{al}^{30}$ studied the safety and efficacy of $120 \mathrm{mg}$ per day of a standardized ginkgo preparation (Egb 761) to placebo in 327 healthy subjects with AD or multi-infarct dementia. Only $50 \%$ of the gingko group and $38 \%$ of the placebo group completed the entire study. Of the 309 subjects in the ITT analysis, and 202 who provided evaluable data at 52 weeks, the ginkgo group showed modest but statistically significant improvement in cognition and in daily living and social behaviour as measured by the Geriatric Evaluation by Relatives Rating Instrument, a cumulative measure of daily living and social behaviour. No difference was noted in the CGIC. Adverse events related to the study drug were enumerated but poorly defined. The lack of standardized gingko preparations in North America and the high dropout rate are limitations of this study.

Recommendation: Ginkgo biloba slightly improves the scores on certain cognitive tests and on some assessment instruments but not others. Therefore, uncertainty remains as to its practical value in the treatment of dementia. Level 1, Class $C$.

\section{Propentofylline}

In a multinational RCT, 260 patients with mild to moderate $\mathrm{AD}$ or vascular dementia $(\mathrm{VaD})$ received $300 \mathrm{mg}$ propentofylline or placebo. ${ }^{31}$ After 12 months, the total patient population showed statistically significant treatment differences in favour of 
propentofylline on global and some cognitive measures and on an ADLscale but no significant treatment differences were found with rating scales performed by the patients. Although all treatment differences for $\mathrm{AD}$ patients were in favour of propentofylline, they only reached statistical significance on one scale.

Recommendation: The results in this single trial are conflicting and propentofylline is not at present considered appropriate for prescription in the treatment of AD. Level 1, Class $C$.

\section{Hydergine}

Hydergine, a metabolic enhancer ${ }^{32}$ may affect cerebral glucose metabolism and multiple neurotransmitters. ${ }^{33}$ Schneider and $\operatorname{Olin}^{34}$ conducted a detailed review limited to placebocontrolled, double-blind, parallel group RCTs in patients with symptoms consistent with dementia. Overall and for the subgroup with $\mathrm{VaD}$, significant benefit was identified across all outcome measures but subjects with probable AD showed only a small effect on the neuropsychological outcomes. The original studies have several limitations. For example, $71 \%$ of the studies (all before 1980) used simpler statistical techniques and reported selective outcomes; definitions of dementia were not uniform and descriptions of the clinical course were poor. The total number of subjects was small (297) and the categorization between $\mathrm{VaD}$ and $\mathrm{AD}$ was not always clearly defined. It is concluded that, at best, there is modest evidence of benefit from hydergine, affecting behaviour more than cognitive functions and more in subjects with $\mathrm{VaD}$ than in those with possible AD.

Recommendation: Overview analyses of hydergine indicate a significant, but clinically modest, effect of hydergine in patients with dementia, especially $\mathrm{VaD}$. The benefits only achieved statistical significance on cognitive-neuropsychological measures. While hydergine appears to be relatively safe, it is not recommended for the management of dementia. Level 1, Class $C$.

\section{Other therapies}

Numerous other drugs proposed for the treatment of dementia have been subjected to study. None of the agents listed in Table 2 can be recommended (Level 1, Classes C or D) on the basis of the information published to date because of inadequate study design, lack of efficacy or effectiveness, lack of replication or the occurrence of unacceptable side effects. ${ }^{35-63}$

\section{Discussion}

We have reviewed seven drugs with regard to their use in the symptomatic treatment of dementia.

Regarding clinical trial design and outcome measures used in studies of medications for $\mathrm{AD}$, we note that many studies have used outcome measures that are foreign to usual clinical practice, including the ADAS, although this was designed to assess the cognitive and behavioural dysfunctions characteristic of AD. ${ }^{64}$ This compound measure consists of a cognitive subscale (ADAS-Cog), often used as the primary outcome measure, and a noncognitive subscale (ADAS-Noncog). Its 11 items test memory, orientation, language and praxis. The maximum score is 70 points, and a higher score indicates a worse performance. It is a reliable tool and a sensitive indicator of dementia progression. $^{64,65} \mathrm{~A}$ longitudinal study of $111 \mathrm{AD}$ patients
Table 2: Other therapies not recommended for the symptomatic treatment of dementia

\begin{tabular}{|c|c|}
\hline $\begin{array}{l}\text { Agents Not Recommended for } \\
\text { Clinical Use }\end{array}$ & $\begin{array}{l}\text { Standards of } \\
\text { Evidence* }\end{array}$ \\
\hline Acetyl L- carnitine (ALCAR) ${ }^{35-37}$ & Level 1, Class C \\
\hline Lecithin $^{38,39}$ & Level 1, Class C \\
\hline Arecholine $e^{40}$ & Level 1, Class C \\
\hline Nimodipine ${ }^{41}$ & Level 1, Class C \\
\hline Velnacrine ${ }^{42}$ & Level 1, Class D \\
\hline Physostigmine ${ }^{43-45}$ & Level 1, Class D \\
\hline Eptastigmine $^{46}$ & Level 1, Class D \\
\hline Phosphatidylserine ${ }^{47}$ & Level 1, Class D \\
\hline Memantine $^{48}$ & Level 1, Class D \\
\hline 4 Aminopyridine (4AP) ${ }^{49}$ & Level 1, Class D \\
\hline Naloxone $^{50}$ & Level 1, Class D \\
\hline Linopirdine $^{51}$ & Level 1, Class D \\
\hline Aniracetam ${ }^{52}$ & Level 1, Class D \\
\hline Milacemide $^{53}$ & Level 1, Class D \\
\hline Nicergolin $^{54}$ & Level 1, Class D \\
\hline Idebenone $^{55}$ & Level 1, Class D \\
\hline Huperzine- $\mathrm{A}^{56}$ & Level 1, Class D \\
\hline 5 - methyltetrahydrofolic acid ${ }^{57}$ & Level 1, Class D \\
\hline Desferrioxamine ${ }^{58}$ & Level 1, Class D \\
\hline Xantinolnicotinate ${ }^{59}$ & Level 1, Class D \\
\hline Bespirdine $^{60}$ & Level 1, Class D \\
\hline Cycloserine $^{61}$ & Level 1, Class D \\
\hline Cyclandelate $^{62}$ & Level 1, Class D \\
\hline Thyrotropin ${ }^{63}$ & Level 1, Class D \\
\hline
\end{tabular}

* As outlined in Table 1

estimated that the change in score on the ADAS-Cog was approximately 9-11 points per year. ${ }^{65}$ However, the clinical relevance of a change for the better by one, two or three points is uncertain and likely to be minimal.

In 1990, in an attempt to make outcome measures for RCTs more relevant, the U.S. Food and Drug Administration (FDA) mandated that all clinical trials of drugs for the treatment of AD must include a clinician's global assessment as a primary outcome measure. ${ }^{66}$ Various such scales have been developed, varying in their administration and in the information used to determine change ${ }^{67}$ but all using a baseline interview as a reference for future assessments of change. The CIBIC is a specific CGIC measure ${ }^{66}$ including a worksheet delineating the domains to be assessed (concentration, orientation, memory, language, behaviour, initiative, and ADL). As it may be inappropriate to preclude interviewing caregivers at follow-up, the CIBIC-Plus was created, in which both the patient and caregiver are interviewed before a rating is made. Although these scales are now required by the FDA, usually as a primary outcome measure, their validity and reliability remain uncertain. We suggest alternative goals for therapy, but are aware that few of them are directly assessed by neuropsychological tests, although some are assessed by rating scales. 
We suggest that the following are reasonable goals for antidementia therapy:

1. Slowing of the course of the disease (measured against the course in appropriate comparison groups) with respect to cognitive and functional decline or leading to institutionalization.

2. Improvement in memory and other cognitive functions.

3. Improvement or maintenance of functional abilities.

4. Improvement in behavioural abnormalities.

5. Improvement in mood/contentedness and quality of life of the patient and/or caregiver.

None of the drug therapies reviewed satisfy all these criteria, although the results in some cases do suggest future strategies for the treatment of this disease. In the donepezil studies, a minority of patients seem to improve in a clinically meaningful manner.

The clinical trials reviewed here have numerous shortcomings in common. Most have focused on statistically significant changes in outcome measures that do not easily translate into meaningful clinical changes. They thus fail to determine whether patients had clinically important changes in function, behaviour, quality of life, need for institutionalization, caregiver burden or health care resource utilization. In the absence of data pertaining to these important clinical outcomes, it is difficult to interpret the results of most of the clinical trials in $\mathrm{AD}$ that have been reported. The duration of many was comparatively short - sometimes less than three months. While this may be sufficient to demonstrate positive effects on a highly sensitive cognitive scale, it is not sufficient to allow for an evaluation of the impact on important clinical outcomes such as function and institutionalization, or on slowing of the disease process. The use of open-label marketing studies for longer term follow-up can provide important information about side effects, but is a weak design for studying effectiveness because it necessitates comparisons with historical controls. This is particularly troublesome given the strength of the placebo effects that have been demonstrated in the clinical trials.

\section{ConClusion}

Over the last fifteen years, many agents have been tested for their effects in assuaging the burden of dementia, either empirically or based upon various rationales. Few have been found to be efficacious but the fact that occasional improvement in cognitive functioning has been shown indicates that the search for relief from a huge personal, social, economic and societal burden may, at last, be appropriately directed. The goals of antidementia therapy suggested above have not yet been attained, but the occasional successes reported to date suggest that they may be attainable.

Although the treatment of dementias is still in its early stages, at least one form of therapy is now approved, albeit with limited effect. This nevertheless represents an important step forward, for the prevalence of Alzheimer's disease is likely to increase in the next few decades. There remains a need for consensus agreement on the goals of therapy and on the most appropriate means for assessment of those new agents subjected to clinical trial. The ability of any drug to influence the quality of life of the patient and of the caregiver for the better should be the most important factor determining its usefulness.

\section{REFERENCES}

1. Canadian Medical Association. Guidelines for Canadian clinical practice guidelines. Ottawa: The Association; 1994.

2. Woolf SH, Battista RN, Anerson GM, et al. Assessing the clinical effectiveness of preventive manoeuvres: analytical principles and systematic methods in reviewing evidence and developing clinical practice recommendations. J Clin Epidemiol 1994;43: 891-905.

3. Patterson CJS, Gauthier S, Bergman H, et al. The recognition, assessment and management of dementing disorders: conclusions from the Canadian conference on dementia. Can Med Assoc J 1999; (Suppl 12): 160.

4. Chatellier G, Lacomblez L. Tacrine (tetrahydroaminoacridine; THA) and lecithin in senile dementia of the Alzheimer type: a multicentre trial. Br Med J 1990;300(6723):495-499.

5. Molloy DW, Guyatt GH, Wilson DB, et al. Effect of tetrahydroaminoacridine on cognition, function and behaviour in Alzheimer's disease. Can Med Assoc J 1991;144:29-33.

6. Gracon SI. Evaluation of tacrine hydrochloride (Cognex) in two parallel-dose studies. Acta Neurol Scanda 1996;165(Suppl): S114-S122.

7. Knapp MJ, Knopman DS, Solomon PR, et al. A 30-week randomized controlled trial of high-dose tacrine in patients with Alzheimer's disease. JAMA1994;271:985-989.

8. Raskind MA, Sadowsky CH, Sigmund WR, et al. Effect of tacrine on language, praxis and noncognitive behavioural problems in Alzheimer's disease. Arch Neurol 1997;54:836-840.

9. Knopman DS, Schneider L, Davis K, et al. Long term tacrine (Cognex) treatment: effects on nursing home placement and mortality. Neurology 1996;47; 166-177.

10. Watkins PB, Zimmerman HJ, Knapp MJ, et al. Hepatotoxic effects of tacrine administration in patients with Alzheimer's disease. JAMA1994;271:992-998.

11. Rogers SL, Friedhoff LT, Donepezil study group. The efficacy and safety of donepezil in patients with Alzheimer's disease: results of a US multicenter randomized double-blind, placebo-controlled trial. Dementia 1996;7:293-303.

12. Rogers SL, Friedhoff LT. Long term efficacy and safety of donepezil in the treatment of Alzheimer's disease: an interim analysis of the results of a US multicenter open label study. Eur Neuropsychopharmacol 1997;8:67-75.

13. Rogers SL, Farlow MR, Doody RS, et al. A 24-week, double-blind placebo controlled trial of donepezil in patients with Alzheimer's disease. Neurology 1998;50:136- 145.

14. Burns A, Rossor M, Hecker J, et al.The effects of donepezil in Alzheimer's disease-results from a multinational trial. Dement Geriatr Cog Disord 1999;10:237-244.

15. Rogers SL, Doody RS, Mohs RC, et al. Donepezil improves cognition and global function in Alzheimer's disease. Arch Intern Med 1998;158:1021-1031.

16. Greenberg SM, Tennis MK, Brown LB, et al. Donepezil therapy in clinical practice. Arch Neurol 2000;57:94-99.

17. Sano M, Ernesto C, Thomas RG, et al. A controlled trial of selegiline, alpha tocopherol or both as treatment for Alzheimer's disease: the $\mathrm{AD}$ cooperative study. New Eng J Med 1997;336:1216-1222.

18. Drachman DA, Leber P. Treatment of Alzheimer's disease: Searching for a breakthrough, settling for less. New Eng J Med 1997;336(17):1245-1247.

19. Gnemmni P, Rossi F, Monteverde A, et al. Selegiline in the treatment of mild to moderate Alzheimer-type dementia. Clin Therap 1990;12:315-322.

20. Campi N, Todeschini GP, Scarzella L, et al. Selegiline vs Lacetylcarnitine in the treatment of Alzheimer-type dementia. Clin Therap 1990;12:306-314.

21. Tariot PN, Cohen RM, Welkowitz JA, et al. Multiple-dose arecholine infusions in Alzheimer's disease. Arch Gen Psychiatry 1988;45:901-905.

22. Lawlor BA, Aisen PS, Green C, et al. Selegiline in the treatment of behavioural disturbances in Alzheimer's disease. Int J Geriatric Psychiatr 1997;12:319-322. 
23. Finali G, Piccirilli M, Oliani C, et al. L-deprenyl therapy improves verbal memory in amnesic Alzheimer patients. Clin Neuro Pharmacol 1991;14:523-536.

24. Finali G, Piccirilli M, Oliani C. Alzheimer-type dementia and verbal memory performances: influence of selegiline therapy. J Neurol Sci 1992;13:141-148.

25. Burke WJ, Roccaforte WH, Wengel SP, et al. L-deprenyl in the treatment of mild dementia of the Alzheimer type: results of a 15month trial. J Am Geriatr Soc 1993;41:1219-1225.

26. Mangoni A, Grassi MP, Frattola M, et al. Effects of a MAO-B inhibitor in the treatment of Alzheimer's disease. Eur Neurol 1991;31(2):100-107.

27. Freedman M, Rewilak D, Xerri T, et al. L-deprenyl in Alzheimer's disease: cognitive and behavioural effects. Neurology 1998; 50(3):660-668.

28. Filip V, Kolibas E for the Czech and Slovak Senile Dementia of Alzheimer Type Study Group. Selegiline in the treatment of Alzheimer's disease: a long-term randomized placebo-controlled trial. J Psychiatry Neurosci 1999;24(3):234-243.

29. Kanowski S, Herrmann WM, Stephan K. Proof of efficacy of the ginkgo biloba special extract EGb 761 in outpatients suffering from mild to moderate primary degenerative dementia of the Alzheimer type or multi-infarct dementia. Pharmacopsychiatry 1996;29(1):47-56.

30. Le Bars PL. A placebo-controlled, double-blind randomised trial of an extract of ginkgo biloba for dementia. JAMA1997;278:13271332.

31. Marcusson J, Rother M, Kittner BA. A 12-month, randomized, placebo-controlled trial of propentofylline (HWA 285) in patients with dementia according to DSM-III. Dement Geriatr Cogn Disord 1997;8:320-328.

32. Thompson TL. Lack of efficacy of hydergine in patients with Alzheimer's disease. New Eng J Med 1990;323:445-448.

33. Van Reekum R, et al. Cognition-enhancing drugs in dementia: A guide to the near future. Can J Psychiatr 1997;42(Suppl.1):35S$50 \mathrm{~S}$.

34. Schneider LS, Olin JT. Overview of clinical trials of hydergine in dementia. Arch Neurol 1994;51:787-798.

35. Thal LJ, Carta A, Clarke WR, et al. A 1-year, multicenter, placebocontrolled study of acetyl-1-carnitine in patients with Alzheimer's disease. Neurology 1996;47:705-711.

36. Spagnoli A, Lucca U, Menasce G, et al. Long-term acetyl-Lcarnitine treatment in Alzheimer's disease. Neurology 1991;41:1726-1732.

37. Rai G, Wriight G, Scott L, et al. Double-blind, placebo-controlled study of acetyl L-carnitine in patients with Alzheimer's dementia. Curr Med Res Opinion 1990;11:638-647.

38. Heyman A, Schmechel D, Wilkinson W, et al. Failure of long-term, high dose lecithin to retard progression of early-onset Alzheimer's disease. J Neural Transmission (Suppl.) 1987;24(2): 279-286.

39. Foster NL, Petersen RC, Gracon SI, et al. An enriched-population, double-blind, placebo-controlled crossover study of tacrine and lecithin in Alzheimer's disease. Dementia 1996;7:260-266.

40. Tariot PN, Cohen RM, Welkowitz JA, et al. Multiple-dose arecholine infusions in Alzheimer's disease. Arch Gen Psychiatry 1988;45:901-905.

41. Tollefson GD. Long term effects of the calcium channel blocker nimodipine (Bay-e-9736) in the management of primary degenerative dementia. Biol Psychiatry 1990;27:1133-1142.

42. Antuono PG. Effectiveness and safety of velnacrine for the treatment of Alzheimer's disease: a double-blind, placebocontrolled study. Arch Int Med 1995;155:1766-1972.

43. Thal LJ, Schwartz G, Sano M, et al. A multicenter double-blind study of controlled-release physostigmine for the treatment of symptoms secondary to Alzheimer's disease. Neurology 1996;47:1389-1395.

44. Sano M, Bel K, Marder K. Safety and efficacy of oral physostigmine in the treatment of Alzheimer's disease. Clin Neuro Pharmacol 1993;16:61-69.

45. Stern RG, Sano M, Mayeux R. Long-term administration of oral physostigmine in Alzheimer's disease. Neurology 1988;38:1837-1841.
46. Canal N, Imbimbo BP. Relationship between pharmacodynamic study and cognitive effects of eptastigmine in patients with Alzheimer's disease. Clin Pharmacol Ther 1996;60:218-228.

47. Delwaide PJ, Gyselynck-Mambourg AM, Hurlet A, et al. Doubleblind randomized controlled study of phosphatidylserine in senile demented patients. Acta Neurol Scand 1986;73:136-140.

48. Fleischhacker WW, Buchgeher A, Schubert H. Memantine in the treatment of senile dementia of the Alzheimer type. Prog Neuropsychopharmacol Biol Psychiatry 1986;10:87-89.

49. Davidson M, Zemishlany Z, Mohs RC, et al. 4-Aminopyridine in the treatment of Alzheimer's disease. Biol Psychiatry 1988;23:485-490.

50. Tariot PN, Sunderland T, Weingartner H, et al. Naloxone and Alzheimer's disease: cognitive and behavioural effects of a range of doses. Arch Gen Psychiatry 1986;43:727-732.

51. Rockwood K, Beattie BL, Eastwood MR, et al. A randomized controlled trial of linopirdine in the treatment of Alzheimer's disease. Can Med Assoc J 1987;24:140-145.

52. Senin U, Abate G, Fieschi C, et al. Aniracetam (Ro 13-5057) in the treatment of senile dementia of Alzheimer type (SDAT): results of a placebo-controlled multicentre clinical study. Eur Neuropsychopharmacol 1991;1:511-517.

53. Dysken MW, Mendels J, Lewitt P, et al. Milacemide: a placebocontrolled study in senile dementia of the Alzheimer type. J Am Geriatr Soc 1992;40:503-506.

54. Hermann WM, Stephan K, Gaede K, et al. A multicenter, randomized double-blind study on the efficacy and safety of nicergoline in patients with multi-infarct dementia. Dement Geriatr Cogn Disord 1997;8:9-17.

55. Bergamasco B, Scarzella L, La Commare P. Idebenone, a new drug in the treatment of cognitive impairment in patients with dementia of the Alzheimer type. Funct Neurol 1994;9:161-168.

56. Xu SS, Gao ZX, Weng Z, et al. Efficacy of tablet huperzine-A on memory, cognition, and behaviour in Alzheimer's disease. Acta Pharmacol Sinica 1995;16:391-395.

57. Passeri M, Cucinotta D, Abate $G$, et al. Oral 5'methyltetrahydrofolic acid in senile organic mental disorders with depression: results of a double-blind multicentre study. Aging 1938;5:63-71.

58. McLachlan DR, Smith WL, Kruck TP. Desferrioxamine and Alzheimer's disease: Video home behaviour assessment of clinical course and measures of brain aluminum. Ther Drug Monit 1993;15:602-607.

59. Kanowski S, Fischhof PK, Grobe-Einsler R, et al. Efficacy of xantinolnicotinate in patients with dementia. Pharmacopsychiatry 1990;23:118-124.

60. Sramek JJ, Viereck C, Huff FJ, et al. A "bridging" (safety/tolerance) study of bespirdine hydrochloride in patients with Alzheimer's disease. Life Sci 1995;57:1241-1248.

61. Fakouki TK, Jhee SS, Shramik JJ, et al. Evaluation of cysloserine in the treatment of Alzheimer's disease. J Geriatr Psychiatry Neurol 1995;8:226-230.

62. Schellenbert R, Todorova A, Wedekind W, et al. Pathophysiology and psycho-pharmacology of dementia - a new study design. 2 . Cyclandelate treatment - placebo-controlled, double-blind clinical trial. Neuropsychobiology 1997;35(3):132-142.

63. Mellor AM, Sunderland T, Cohen RM, et al. Acute effects of highdose thyrotropin releasing hormone infusions in Alzheimer's disease. Psychopharmacology 1989;98:403-407.

64. Rosen WG, Mohs WC, Davis KL. A new rating scale for Alzheimer's disease. Am J Psychiatry 1984;141:1356-1364.

65. Stern RG, Mohs RC, Davidson M, et al. A longitudinal study of Alzheimer's disease: measurement, rate and predictors of cognitive deterioration. Am J Psychiatry 1994;151:390-396.

66. Knopman DS, Knapp MJ, Gracon SI, et al. The Clinician InterviewBased Impression (CIBI): a clinicians global change rating scale in Alzheimer's disease. Neurology 1994;44:2315-2321.

67. Schneider LS, Olin JT, Doody RS, et al. Validity and reliability of the Alzheimer's disease Cooperative study - Clinical Global Impression of Change. Alzheimer Dis Assoc Disord 1997;11(Suppl 2):S22-S32. 